\title{
Chromium and Copper-Doped Magnetite Catalysts for the High
}

\section{Temperature Shift Reaction}

\author{
Emerentino Brazil Quadro, Maria de Lourdes Ribeiro Dias, Adelaide Maria \\ Mendonça Amorim, and Maria do Carmo Rangel
}

Instituto de Química, Universidade Federal da Bahia, 40170-280 Salvador - Ba, Brazil

Foi obtida magnetita pura e dopada com cromo e cobre, visando produzir catalisadores, na fase ativa, destinados à conversão de monóxido a dióxido de carbono a altas temperaturas (reação de HTS). As amostras foram preparadas por aquecimento do hidroxoacetato de misto ferro (III), IHA, na faixa de $150-400{ }^{\circ} \mathrm{C}$, e caracterizados por análise química, difração de raios-X, análise térmica (DSC e TG), espectroscopia no infravermelho, medidas de área específica, microscopia eletrônica de varredura e microssonda eletrônica de raios X. Observou-se que a presença do cobre favorece a formação da magnetita mas não afeta a cristalinidade dos sólidos, de modo significativo. Ambos os dopantes melhoram o desempenho dos catalisadores: o cromo atua como estabilizador, enquanto o cobre aumenta a atividade intrínseca. Entretanto, este último favorece a sinterização, levando à formação de sólidos com baixas áreas superficiais. O efeito sinérgico desses dopantes é aumentar a atividade catalítica e a área superficial dos sólidos.

Copper and chromium-doped magnetite was prepared to be used as catalysts, in the active phase, in the high temperature shift (HTS) reaction. Samples were produced by heating a mixed hydrate ferric oxyhydroxide (IHA) in the range of $150-400{ }^{\circ} \mathrm{C}$ and characterized by means of chemical analysis, X-ray diffraction, thermal analysis (DSC and TG), infrared spectroscopy, surface area measurements, scanning electron microscopy and X-ray microanalysis. It was found that copper favors magnetite formation but does not affect significantly the crystallinity of the solids. Both chromium and copper improve the performance of the catalysts towards the HTS reaction: chromium acts as a stabilizer whereas copper increases the intrinsic activity. However, copper favors sinterization leading to solids with low surface areas. The increase in the catalytic activity and in the surface area of the solids reflects the synergy of these dopants.

Keywords: magnetite formation, chromium and copper-doped magnetite, HTS catalyst

\section{Introduction}

The water gas shift reaction ${ }^{1}$ :

$$
\begin{aligned}
& \mathrm{CO}_{(\mathrm{g})}+\mathrm{H}_{2} \mathrm{O}_{(\mathrm{g})} \rightleftharpoons \mathrm{CO}_{2(\mathrm{~g})}+\mathrm{H}_{2(\mathrm{~g})} \\
& \Delta \mathrm{H}=-40,6 \mathrm{~kJ} \mathrm{~mol}^{-1} .
\end{aligned}
$$

is an important step in industrial processes to produce highly pure hydrogen. It is favored by low temperatures and excess of steam due to its reversibility and exothermicity, but it takes high temperatures to achieve suitable rates for commercial applications. As a consequence, this reaction is often carried out in two steps, the first being performed in the range of $320-450{ }^{\circ} \mathrm{C}$ (named high temperature shift, HTS) whereas, in the other, carbon monoxide is removed in thermodynamically favorable conditions, at $200-250{ }^{\circ} \mathrm{C}$ (low temperature shift, LTS $)^{2}$.
The HTS stage is carried out over three catalytic fixed beds of chromia-doped iron oxides, commercialized as hematite $\left(\alpha-\mathrm{Fe}_{2} \mathrm{O}_{3}\right)$. This compound is reduced in situ to produce magnetite $\left(\mathrm{Fe}_{3} \mathrm{O}_{4}\right)$ which is found to be the active phase $^{1-3}$. This reaction is highly exothermic and should be controlled to avoid the production of metallic iron, which may catalyze undesirable reactions such as hydrocarbon generation ${ }^{2}$. In industrial processes, large amounts of steam are used to inhibit the metallic iron formation. However, this implies high operational costs which lead to the need for developing the catalyst in the active phase.

The chromium and iron-based catalysts have been used in commercial processes for more than sixty years and show high stability and performance. In recent times, these solids have been improved by adding small amounts of copper, resulting in more active and selective catalysts. They have 
already been used in industrial plants and are able to work in more severe conditions, e.g. lower steam to carbon ratios without being reduced to metallic iron. Therefore, these systems offer greater operating flexibility as compared to the classic HTS catalysts; the highest activity allows the use of smaller bed volume without affecting the plant performance; the protection against metallic iron formation, and hence hydrocarbon production, saves hydrogen and requires lower operating temperatures reducing catalyst sintering rates to ensure long life.

The chromium and iron- based catalysts have been extensively studied. A lot of work has been carried out concerning their activity, selectivity and mechanical strength as well as their resistance against sulphur ${ }^{4-6}$. The role of chromium was also considered; it is believed to increase the surface area of the solids preventing sintering and thus increasing their life ${ }^{1-3}$.

On the other hand, there are few works in the open literature about the copper and chromium-doped iron oxides, as HTS catalysts, despite their commercial importance $^{7,8}$.

Considering these aspects, this work describes a method of preparation to produce this catalyst in the active form, in order to avoid the reduction step before the HTS reaction; this procedure offers the possibility of increasing the life of the catalyst as well as the process efficiency due to the energy saved.

In a previous work ${ }^{9}$, we found that heating of chromium-doped iron (III) hydroxoacetate (IHA) is a convenient method to prepare chromium-doped magnetite, useful as catalysts for the HTS reaction. In the present paper, we continued these studies by using this method to produce the copper and chromium-doped magnetite.

\section{Experimental}

All reagents used were of an analytical grade.

Samples were prepared by heating IHA, a hydrate ferric oxyhydroxide, amorphous to X-ray ${ }^{10}$, doped with copper, chromium or both, in the range of $150-400{ }^{\circ} \mathrm{C}$. The magnetite formation was followed by determining the amount of $\mathrm{Fe}$ (II) in solids as well as by X-ray diffraction and by thermal analysis (DSC and TG). Infrared spectroscopy, surface area measurements, scanning electron microscopy and X-ray microanalysis were also used to characterize the materials produced.

The IHA precursors were prepared by reverse coprecipitation techniques at room temperature, followed by heating under nitrogen $(100 \mathrm{~mL} / \mathrm{min})$ in the range of 150 $400{ }^{\circ} \mathrm{C}$, for two hours. Different $\mathrm{Fe} / \mathrm{Cu}$ molar ratios were used $(\mathrm{Fe} / \mathrm{Cu}=55$ and 35$)$ whereas the amount of chromium in solids was kept the same in all cases, in a value close to those of the commercial formulations $(\mathrm{Fe} / \mathrm{Cr}=10)$. Plain IHA was also prepared to be used as a reference.
The copper-doped samples $(\mathrm{Fe} / \mathrm{Cu}=55)$ were produced by adding $250 \mathrm{~mL}$ of an aqueous solution with $1.079 \mathrm{~g}$ of $\mathrm{Cu}\left(\mathrm{NO}_{3}\right)_{2} .3 \mathrm{H}_{2} \mathrm{O}$ and another with $101.0 \mathrm{~g}$ of $\mathrm{Fe}\left(\mathrm{NO}_{3}\right)_{3}$. $9 \mathrm{H}_{2} \mathrm{O}$ to $150 \mathrm{~mL}$ of $6 \mathrm{~N}$ sodium hydroxide solution under stirring. The final $\mathrm{pH}$ was adjusted to 11 and the system was kept under stirring for $30 \mathrm{~min}$. The sol produced was centrifuged (2000 rpm, $5 \mathrm{~min}$ ) and the gel rinsed with water at $60^{\circ} \mathrm{C}$, to remove sodium and nitrate ions from the starting materials. The supernatant was analyzed for nitrate ions and the gel was washed and centrifuged again. After this, it was rinsed with $100 \mathrm{~mL}$ of $5 \%$ (w/v) ammonium acetate solution in order to promote acetate sorption on iron (III) hydroxide 9,10 and the resultant material was dried in an oven at $120{ }^{\circ} \mathrm{C}$. The same procedure was followed to prepare samples with $\mathrm{Fe} / \mathrm{Cu}=35$, by using an amount of $1.7427 \mathrm{~g}$ of copper nitrate.

In the preparation of chromium-doped samples, $10.1 \mathrm{~g}$ of $\mathrm{Cr}\left(\mathrm{NO}_{3}\right)_{3} .9 \mathrm{H}_{2} \mathrm{O}$ was used instead of copper nitrate in the method described above.

The chromium and copper-doped solids were produced by adding the three solutions simultaneously, in the method described above. The same method was also used to prepare the plain samples.

The qualitative analysis of nitrate was performed by adding about $1 \mathrm{~mL}$ of concentrated sulfuric acid to $10 \mathrm{~mL}$ of supernatant after centrifugation. The $[\mathrm{Fe}(\mathrm{NO})]^{2+}$ formation was detected by a brown ring ${ }^{11}$. The absence of nitrate in the solids was confirmed by infrared spectroscopy. To determine the iron content, the solids were dissolved in concentrated hydrochloric acid, under reflux for $10 \mathrm{~min}$. After reducing $\mathrm{Fe}$ (III) to $\mathrm{Fe}(\mathrm{II})$ with stannous chloride, the solution was titrated with potassium dichromate. The analysis of $\mathrm{Fe}$ (II) content was carried out on fresh and on used catalysts to follow the magnetite formation from IHA and its stability under the reaction atmosphere, respectively. The samples were dissolved in concentrated hydrochloric acid, under a carbon dioxide atmosphere and then titrated with potassium dichromate ${ }^{12}$. The amount of chromium in the solids was determined by adding ammonium iron (II) sulfate to fused samples to reduce $\mathrm{Cr}$ (VI) to $\mathrm{Cr}$ (III), followed by back titration of excess of $\mathrm{Fe}(\mathrm{II})$ with potassium dichromate ${ }^{13}$. The copper and sodium contents were analyzed by atomic absorption in a Perkin Elmer 703 equipment. Carbon analysis was carried out using a model LECO 761-100 apparatus.

Infrared spectra in the range of $4000-650 \mathrm{~cm}^{-1}$ were taken in a Shimadzu IR-430 spectrometer from KI discs. $\mathrm{X}$-ray diffractograms were recorded at room temperature with a Philips PW 1130 instrument using $\mathrm{Cu} \mathrm{K} \alpha$ radiation, at a rate of 2 degrees/min. The surface areas were measured in a CG 2000 apparatus (BET method).

Magnetite formation was monitored by carrying out thermal analysis experiments (DSC and TG) at a heating 
rate of $10{ }^{\circ} \mathrm{C} / \mathrm{min}$, under nitrogen atmosphere (100 mL/min) using a Du Pont 9900 instrument.

$\mathrm{X}$-ray microanalysis were performed in a microprobe Noran attached to a Jeol JSM-T300 microscope operating at $20-30 \mathrm{KV}$.

In order to evaluate the performance of the catalysts, 0.2 $\mathrm{cm}^{3}$ of powder within -250 and +325 mesh size was used in a fixed bed microreactor consisting of a stainless tube. All experiments were carried out under isothermal conditions $\left(370^{\circ} \mathrm{C}\right)$ and at atmospheric pressure, providing there is no diffusion effect. A gas composition around $8.1 \% \mathrm{CO}$, $5.3 \% \mathrm{CO}_{2}, 47.8 \% \mathrm{H}_{2} 38.4 \mathrm{~N}_{2}$ and $0.2 \% \mathrm{CH}_{4}$ and a steam $/$ gas $=0.6$ were employed. The gaseous effluent was analyzed by on line gas chromatography, using a CG-35 instrument, with a thermal conductivity detector (at $100^{\circ} \mathrm{C}$ ) and a $13 \mathrm{X}$ sieve molecular column $\left(2 \mathrm{~m}, 1 / 8^{\prime \prime}\right)$, at $40{ }^{\circ} \mathrm{C}$, using hydrogen as carrier $(30 \mathrm{~mL} / \mathrm{min})$. The reaction was followed by monitoring the carbon monoxide concentration in the stream. A commercial catalyst, based on iron, chromium and copper $\left(87 \% \mathrm{Fe}_{2} \mathrm{O}_{3}, 10 \% \mathrm{Cr}_{2} \mathrm{O}_{3}, 3 \% \mathrm{CuO}\right)$ was used to compare the performance of the solids prepared. After each experiment, the $\mathrm{Fe}(\mathrm{II}) / \mathrm{Fe}(\mathrm{III})$ ratio was measured to follow the iron reduction under the reaction atmosphere.

\section{Results}

Table 1 shows the results of iron, carbon, chromium, sodium and copper analysis. We can see that in copperdoped samples, the experimental $\mathrm{Fe} / \mathrm{Cu}$ relation is close to the initial ratio when the sample has a low amount of copper. However, in the presence of chromium the reverse behavior is noted. On the other hand, the $\mathrm{Fe} / \mathrm{Cr}$ ratios are smaller than the values of the starting solutions (10) indicating a high level of precipitation of the chromium compounds as compared to the iron ones.

As ammonia can be complexed by copper in aqueous medium, yielding a blue and soluble compound ${ }^{14}$, $\left[\mathrm{Cu}\left(\mathrm{NH}_{3}\right)_{4}\right]^{2+}$, sodium hydroxide was used instead of ammonium hydroxide to precipitate the mixed IHA. As shown in Table 1, the residual amount of sodium from the precipitate depends on the presence of the dopants as well as on

Table 1. $\mathrm{Fe} / \mathrm{Na}, \mathrm{Fe} / \mathrm{Cr}, \mathrm{Fe} / \mathrm{Cu}$ and $\mathrm{Fe} /$ acetate molar ratio for plain and doped IHA.

\begin{tabular}{lcccc}
\hline Sample & $\begin{array}{c}\mathrm{Fe} / \mathrm{Na} \\
\pm 0.2)\end{array}$ & $\begin{array}{c}\mathrm{Fe} / \mathrm{Cr} \\
( \pm 0.2)\end{array}$ & $\begin{array}{c}\mathrm{Fe} / \mathrm{Cu} \\
( \pm 0.2)\end{array}$ & $\begin{array}{c}\mathrm{Fe} / \text { Acetate } \\
( \pm 0.2)\end{array}$ \\
\hline IHA & 10.4 & - & - & 5.4 \\
Cr & 6.3 & 5.3 & - & 7.0 \\
Cu55 & 7.1 & - & 54.0 & 4.2 \\
Cu35 & 6.2 & - & 30.2 & 4.4 \\
CrCu55 & 6.0 & 4.7 & 45.6 & 5.6 \\
CrCu35 & 5.1 & 3.9 & 38.9 & 6.5 \\
\hline
\end{tabular}

their contents; the largest amount was detected in the plain sample. The acetate sorption also changes due to the dopant as it can be inferred by the iron to acetate molar ratios.

The solids darkened and became magnetic under heating. In all samples, the $\mathrm{Fe}(\mathrm{II}) / \mathrm{Fe}(\mathrm{III})$ ratios increased with heating; at about $350{ }^{\circ} \mathrm{C}$, they reached values close to the stoichiometric ratio of magnetite (0.5). The curves differed quantitatively in each case, depending on the presence and on the amount of the dopant. Figure 1 illustrates this behavior for samples with $\mathrm{Fe} / \mathrm{Cu}=35$ (with or without chromium), chromium-doped solids and the plain materials. As we can see, at lower temperatures chromium itself does not affect the $\mathrm{Fe}(\mathrm{III})$ reduction whereas copper delays this process in the presence or absence of chromium. However, above $300{ }^{\circ} \mathrm{C}$ the reduction is favored by copper and, as a synergetic effect of the dopants, this ratio is increased even more. It occurs independently of the amount of copper, as noted by the final values of this ratio, in each case (Table 2).

The residual amount of carbon from the carboxylate decomposition is around $0.5 \%$ (Table 2). The carbon content can avoid the addition of graphite, often used as pelletization agent, in commercial formulations of the HTS catalysts $^{13}$. Sodium also remained in the solids after heating in a range of $0.8-4.4 \%$.

$\mathrm{X}$-ray diffractograms, taken after heating at several temperatures, for $2 \mathrm{~h}$ under nitrogen, did not show any discrete diffraction lines for solids heated to 150 and $200{ }^{\circ} \mathrm{C}$. Heating at $250{ }^{\circ} \mathrm{C}$ diffuse lines appear and become more intense as the temperature increases. Figure 2 illustrates this profile for the samples with copper and chromium $(\mathrm{Fe} / \mathrm{Cu}=35)$.

At $400{ }^{\circ} \mathrm{C}$, the diffractograms show the pattern of magnetite $^{16}$ as we can see in Fig. 3 . It can also be noted that both copper and chromium delay crystallization; it is evidenced by a broadening of the diffraction lines as well as by a decrease in their intensities.

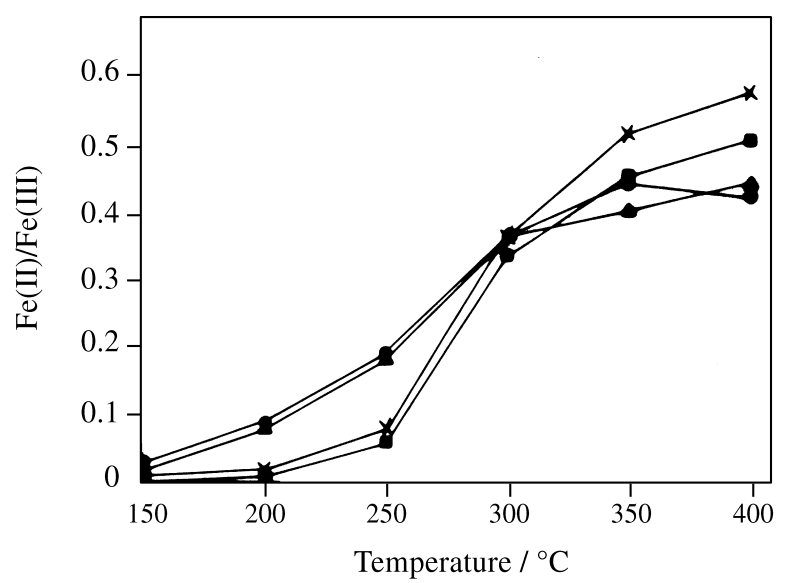

Figure 1. $\mathrm{Fe}(\mathrm{II}) / \mathrm{Fe}(\mathrm{III})$ ratio in plain and doped IHA $(\mathrm{Fe} / \mathrm{Cu}=35)$ as a function of the heating temperature $\bullet \mathrm{IHA} ; \Delta \mathrm{Cr} ; \square \mathrm{Cu} ; \mathrm{x} \mathrm{CrCu}$. 
Table 2. $\mathrm{Fe}(\mathrm{II}) / \mathrm{Fe}(\mathrm{III})$ molar ratio and the amount of carbon and sodium for plain and doped IHA after heating at $400{ }^{\circ} \mathrm{C}$.

\begin{tabular}{|c|c|c|c|c|c|c|c|}
\hline Sample & $\% \mathrm{Fe}( \pm 0.1)$ & $\begin{array}{c}\% \mathrm{Fe}(\mathrm{II}) \\
( \pm 0.1)\end{array}$ & $\begin{array}{c}\frac{\mathrm{Fe}(\mathrm{II})}{\mathrm{Fe}(\mathrm{III})} \\
( \pm 0.1)\end{array}$ & $\begin{array}{c}\% \mathrm{Cr} \\
( \pm 0.1)\end{array}$ & $\begin{array}{c}\% \mathrm{Cu} \\
( \pm 0.1)\end{array}$ & $\begin{array}{c}\% \mathrm{C} \\
( \pm 0.1)\end{array}$ & $\begin{array}{c}\% \mathrm{Na} \\
( \pm 0.1)\end{array}$ \\
\hline IHA & 72.2 & 21.7 & 4.3 & - & - & 0.4 & 4.4 \\
\hline $\mathrm{Cr}$ & 60.5 & 18.8 & 4.5 & 14.5 & - & 0.2 & 1.1 \\
\hline $\mathrm{Cu} 55$ & 70.3 & 23.9 & 4.9 & - & 1.6 & 0.6 & 3.9 \\
\hline $\mathrm{Cu} 35$ & 72.6 & 24.6 & 5.1 & - & 2.6 & 0.4 & 1.4 \\
\hline $\mathrm{CrCu} 55$ & 57.0 & 20.2 & 5.5 & 16.0 & 1.2 & 0.5 & 1.0 \\
\hline $\mathrm{CrCu} 35$ & 58.3 & 21.5 & 5.8 & 13.0 & 1.6 & 0.6 & 0.8 \\
\hline
\end{tabular}

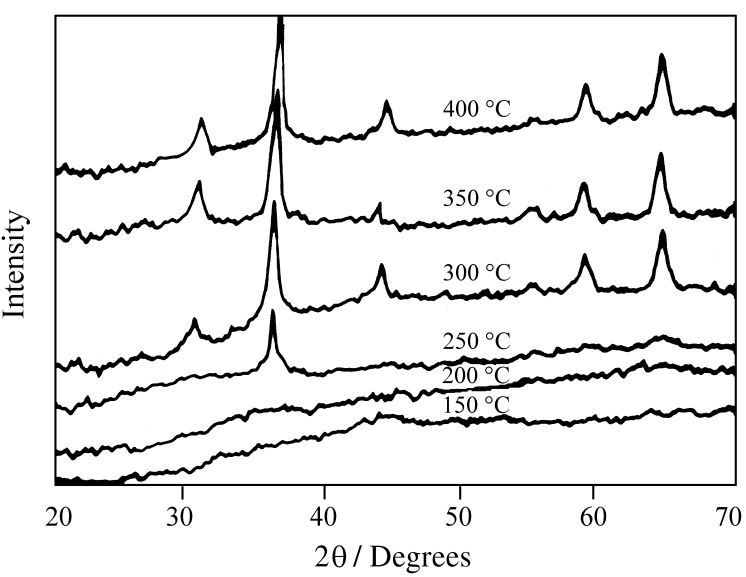

Figure 2. X-ray diffractograms of $\mathrm{Cr}$ - and $\mathrm{Cu}$-doped $\mathrm{IHA}(\mathrm{Fe} / \mathrm{Cu}=35)$ after heating at several temperatures for $2 \mathrm{~h}$ under nitrogen.

From the interplanar spacing values (Table 3) we can note that all dopants enter the magnetite lattice under the experimental conditions used in this work. By comparing the values of the plain samples with those of the ASTM card $^{16}$, it is seen that sodium increases the parameters of magnetite, as pointed out earlier ${ }^{17}$. In spite of its large radius, this ion can easily enter the spinel strucuture due to its lower electronegativity $(0.9)$ as compared to that of $\mathrm{Fe}(\mathrm{II})$ (1.65) and $\mathrm{Fe}$ (III) (1.83); as a result, stronger bonds (Na-O) are produced, as compared to $\mathrm{Fe}-\mathrm{O}$ ones ${ }^{18}$.

On the other hand, chromium leads to a shrinkage of the unit cell due to its smaller radius $(0.63 \mathrm{~A})$ as compared to that of $\mathrm{Fe}(\mathrm{II})(0.74 \mathrm{~A})$. It has been accepted that the $\mathrm{Cr}$ (III) ion has an octahedral preference due to its stabilization energy in the octahedral field ${ }^{19}$ and thus substitutes $\mathrm{Fe}(\mathrm{II})$ ion during the spinel formation; as a consequence, the $\mathrm{Fe}$ (II) replaced is further oxidized to Fe(III) (0.69 A) increasing the shrinkage even more.

However, $\mathrm{Cu}$ (II) (0.72 A) does not readily substitute $\mathrm{Fe}$ (II) $(0.74 \mathrm{~A})$, in spite of its stabilization energy; this may be attributed to its higher electronegativity leading to $\mathrm{Cu}-\mathrm{O}$ bonds which are weaker than Fe-O bonds. This had been evidenced by studying natural systems such as silicate

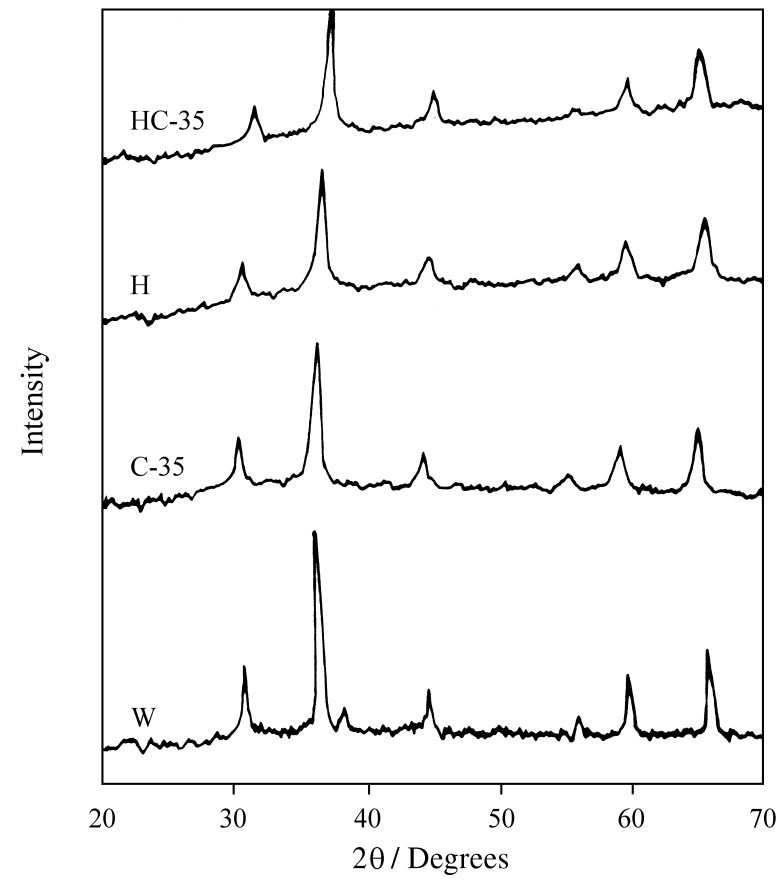

Figure 3. X-ray diffractograms of plain and doped IHA $(\mathrm{Fe} / \mathrm{Cu}=35)$ previously heated at $400{ }^{\circ} \mathrm{C}$ for $2 \mathrm{~h}$ under nitrogen.

minerals in which copper does not enter the structure during magmatic crystallization but rather accumulates in the residual magma until a concentration sufficient to precipitate $\mathrm{CuFeS}_{2}$ is reached ${ }^{18}$.

Another phase like chromium oxide was not detected; neither was wustite, despite the high amount of Fe(II) in the solids.

Infrared spectroscopy was used to confirm the presence of acetate in solids, by the detection of the absorption bands at 1530 and $1410 \mathrm{~cm}^{-1}$, assigned to the symmetric and asymmetric stretching modes ${ }^{20}$ as well as the bands at 3350 and $1330 \mathrm{~cm}^{-1}$ due to the hydroxyl and nitrate groups, respectively ${ }^{21}$.

Table 4 shows the surface areas of plain and doped IHA before and after heating under nitrogen at $400{ }^{\circ} \mathrm{C}$ for $2 \mathrm{~h}$. All solids have large areas before heating, but they present 
Table 3. Interplanar spacings (d) for plain and doped IHA after heating at $400{ }^{\circ} \mathrm{C}$.

\begin{tabular}{lccccccc}
\hline hkl & $\begin{array}{c}\text { ASTM card } \\
\text { N. 19269 }\end{array}$ & \multicolumn{7}{c}{$\mathrm{d}(\mathrm{A})$} \\
\cline { 3 - 8 } & & $\mathrm{M}$ & $\mathrm{Cr}$ & $\mathrm{Cu} 55$ & $\mathrm{Cu} 35$ & $\mathrm{CrCu} 55$ & $\mathrm{CrCu} 35$ \\
\hline 220 & 2.996 & 3.00 & 2.95 & 2.99 & 2.96 & 3.00 & 3.00 \\
311 & 2.530 & 2.55 & 2.51 & 2.54 & 2.52 & 2.53 & 2.53 \\
222 & 2.419 & 2.44 & -- & 2.44 & - & - & - \\
400 & 2.096 & 2.11 & 2.08 & 2.11 & 2.09 & 2.09 & 2.10 \\
422 & 1.712 & 1.72 & 1.70 & 1.72 & - & 1.71 & - \\
$333 / 511$ & 1.614 & 1.62 & 1.60 & 1.62 & - & 1.61 & 1.61 \\
440 & 1.483 & 1.49 & 1.47 & 1.49 & - & 1.48 & 1.48 \\
\hline
\end{tabular}

different resistance against sintering. Copper does not act as a textural promoter but rather favors the loss of area; in the presence of chromium, however, this process is delayed. As expected ${ }^{1,2,9}$, chromium makes magnetite sintering more difficult.

Thermal analysis was performed on IHA samples to monitor the effect of copper on the magnetite formation. However, due to the low amount of this dopant, as well as to the presence of sodium in solids, this effect was not noted. In all cases there was an endothermic peak below $150{ }^{\circ} \mathrm{C}$ due to the loss of volatile components ${ }^{9,22}$ and an exothermic one around $320{ }^{\circ} \mathrm{C}$, due to magnetite formation $^{9}$. The thermograms of the chromium-doped IHA show, in addition, an exothermic peak around $244^{\circ} \mathrm{C}$, associated to dehydration ${ }^{23}$. An exothermic peak at $450{ }^{\circ} \mathrm{C}$, due to the production of crystalline chromium oxide ${ }^{24}$, was not detected.

As illustrated in Fig. 4, electron scanning micrographs show coarse particles of variable sizes and shapes, with several fissures and other imperfections. This fact can be attributed to the numerous factors (e.g. $\mathrm{pH}$ and gradients of concentration) which affect the reactions involved in the ferric hydrous oxides precipitation; in this way, a small change in the preparation conditions may yield different kinds of precipitates ${ }^{25}$.

From the experiments with the $\mathrm{X}$-ray microprobe it was noted that copper is not distributed evenly on the surface in the $100 \mu \mathrm{m}$ range and this effect is more intense in chromium-doped solids. In contrast, chromium is more evenly distributed on the surface in all samples. Figure 4 shows a view of chromium and iron distribution; we note that they do overlap in the size of 10-100 $\mu \mathrm{m}$. By comparing the chemical analysis results with the average values found by X-ray microanalysis (Table 5) we see that most of the chromium is inside the solid. In the same way, copper is distributed non-uniformly along the structure as proposed by Sidhu et al. ${ }^{26}$ In chromium-free samples, it tends to
Table 4. Surface area $\left(\mathrm{m}^{2} / \mathrm{g}\right)$ of plain and doped IHA before and after heating at $400{ }^{\circ} \mathrm{C}$.

\begin{tabular}{lrrrrrc}
\hline Sample & IHA & Cr & Cu55 & Cu35 & CrCu55 & CrCu35 \\
\hline Before & 212 & 223 & 240 & 222 & 198 & 235 \\
After & 20 & 75 & 15 & 13 & 59 & 79 \\
\hline
\end{tabular}

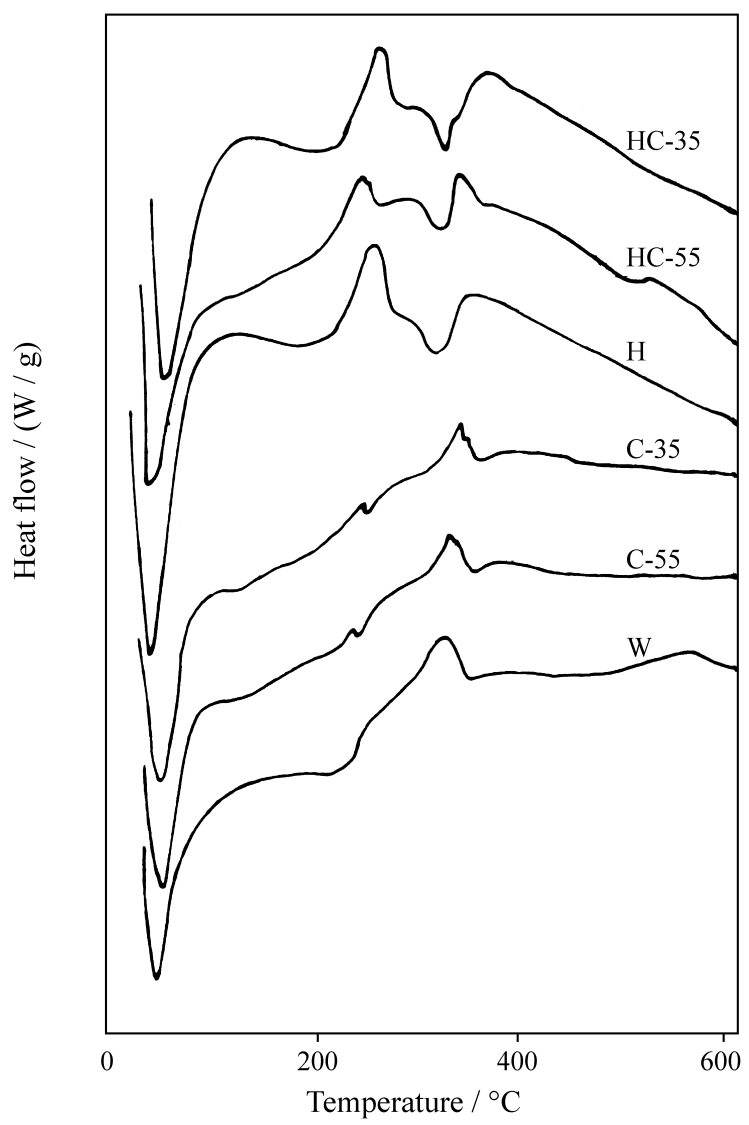

Figure 4. Scanning electron micrographs taken from $\mathrm{Cr}$ - and $\mathrm{Cu}$-doped IHA heated at $400{ }^{\circ} \mathrm{C}$.

migrate to the surface, but in the presence of chromium, it goes from the surface. 
Table 5. $\mathrm{Fe} / \mathrm{Cr}$ and $\mathrm{Fe} / \mathrm{Cu}$ molar ratio of doped IHA obtained by chemical analysis and by X-ray microanalysis after heating at $400{ }^{\circ} \mathrm{C}$.

\begin{tabular}{lcccc}
\hline Sample & \multicolumn{2}{c}{ Chemical Analysis } & \multicolumn{2}{c}{$\begin{array}{c}\text { X-ray microprobe } \\
\text { (average values) }\end{array}$} \\
\hline & $\mathrm{Fe} / \mathrm{Cr}$ & $\mathrm{Fe} / \mathrm{Cu}$ & $\mathrm{Fe} / \mathrm{Cr}$ & $\mathrm{Fe} / \mathrm{Cu}$ \\
\hline $\mathrm{Cr}$ & 5.3 & - & 10.1 & - \\
$\mathrm{Cu} 55$ & - & 54.0 & - & 33.6 \\
$\mathrm{Cu} 35$ & - & 30.2 & - & 34.0 \\
$\mathrm{CrCu} 55$ & 4.7 & 45.6 & 9.7 & 68.6 \\
$\mathrm{CrCu} 35$ & 3.9 & 38.9 & 9.4 & 41.6 \\
\hline
\end{tabular}

Table 6 presents the results of the catalytic activity towards the HTS reaction as well as the $\mathrm{Fe}(\mathrm{II}) / \mathrm{Fe}(\mathrm{III})$ ratio of fresh and used catalysts.

In agreement with results of several authors ${ }^{1-3}$ chromium-doped iron oxides are more active than the plain solids and this is due to the action of chromium as textural promoter. In fact, we found that the activity per unit area of chromium-doped magnetite is lower than that of the pure iron oxide. In contrast, copper favors sintering as shown in Table 4. Because of this, the copper-doped solids show activities close to that of the plain catalyst, in spite of their higher activities per unit area. In doped-samples with both chromium and copper, there is a better performance only in solids with greater amounts of copper $(\mathrm{Fe} / \mathrm{Cu}=35)$, since chromium tends to cause a decrease in the activity per unit area. As magnetite is the active phase we can consider that the activity per unit area is closely related to the intrinsic activity. We can thus conclude that copper acts as a structural promoter in iron-based catalysts whereas chromium leads to a decrease in the intrinsic activity. The chromiumdoped magnetite with $\mathrm{Fe} / \mathrm{Cu}=35$ showed a better performance than a commercial catalyst based on copper and chromium-doped hematite $\left(25.0 \times 10^{-3} \mathrm{~mol} \mathrm{~g}^{-1} \mathrm{~h}^{-1}\right)$.

From the values of the $\mathrm{Fe}(\mathrm{II}) / \mathrm{Fe}(\mathrm{III})$ ratio of fresh and used catalysts it can be noted that magnetite underwent further reduction in the atmosphere of the HTS reaction, reaching values higher than the stoichiometric value of magnetite. However, it seems that the performance of the catalysts is not altered.

\section{Discussion}

It is well-known ${ }^{27-32}$ that $\mathrm{Fe}(\mathrm{III})$ and $\mathrm{Cr}$ (III) ions exhibit very different behaviors towards hydrolysis and condensation in aqueous solutions, despite their similar electronegativities and coordination numbers. Both form octahedral complexes, but $\mathrm{Fe}(\mathrm{III})$ produces very reactive polycations ${ }^{31}$ while $\mathrm{Cr}(\mathrm{III})$ leads to stable ones ${ }^{32}$. This can be correlated with the high rate of condensation of the aquo-hydroxo precursors of $\mathrm{Fe}$ (III) ions in contrast with $\mathrm{Cr}$ (III) ions. Due to the $3 \mathrm{~d}^{3}$ electronic configuration, both olation and oxola-
Table 6. Catalytic activity (a), catalytic activity per area(a*) and $\mathrm{Fe}(\mathrm{II}) / \mathrm{Fe}(\mathrm{III})$ ratio of plain and doped magnetite.

\begin{tabular}{lcccc}
\hline Sample & $\begin{array}{c}\mathrm{a} \mathrm{x}^{2} 0^{3} \\
\left(\mathrm{~mol} \mathrm{~g}^{-1} \mathrm{~h}^{-1}\right)\end{array}$ & \multicolumn{2}{c}{$\begin{array}{c}\mathrm{Fe}(\mathrm{II}) / \mathrm{Fe}(\mathrm{III}) \times 10 \\
( \pm 0.1)\end{array}$} & \begin{tabular}{c}
$\mathrm{a}^{*} \times 10^{4}$ \\
\cline { 3 - 4 }
\end{tabular} \\
\cline { 3 - 4 } & & $\begin{array}{c}\text { Fresh } \\
\text { catalyst }\end{array}$ & $\begin{array}{c}\text { Used } \\
\text { catalyst }\end{array}$ & \\
\hline $\mathrm{M}$ & 8.4 & 4.3 & 5.5 & 4.2 \\
$\mathrm{Cr}$ & 17.5 & 4.5 & 7.1 & 2.3 \\
$\mathrm{Cu} 55$ & 9.7 & 4.9 & 8.2 & 6.5 \\
$\mathrm{Cu} 35$ & 11.7 & 5.1 & 9.1 & 9.0 \\
$\mathrm{CrCu} 55$ & 19.4 & 5.5 & 8.8 & 3.3 \\
$\mathrm{CrCu} 35$ & 29.8 & 5.8 & 11.1 & 3.8 \\
\hline
\end{tabular}

tion are rather slow processes for $\mathrm{Cr}(\mathrm{III})$ which allowed a detailed study as a function of $\mathrm{pH}^{33}$; this is related to its high crystal field stabilization in the octahedral symmetry. The most crystal field-stabilized ion would be the least hydrolyzed since $\mathrm{OH}^{-}$presumably produces a weaker field than $\mathrm{H}_{2} \mathrm{O}$. In contrast, olation reaction rates must be decreased as the crystal field stabilization increases, since it implies a decrease of the reactivity of the cation towards the ligand exchange. In fact, chromium complexes are known to be strongly iner ${ }^{28}$ with several chemical species in slow equilibrium formed simultaneously as the $\mathrm{pH}$ increases. On the other hand, $\mathrm{Fe}(\mathrm{III})$ cation $\left(3 \mathrm{~d}^{5}\right)$ exhibits no crystal field stabilization in the same symmetry and thus the rates of hydrolysis and polymerization are higher than those of the $\mathrm{Cr}(\mathrm{III})$ ions. As a consequence, $\mathrm{Cr}$ (III) ions produce amorphous gels whose compositions range from $\mathrm{Cr}(\mathrm{OH})_{3}\left(\mathrm{OH}_{2}\right)_{3}$ to $\mathrm{Cr}_{2} \mathrm{O}_{3}{ }^{28,33}$ while $\mathrm{Fe}$ (III) ions form gelatinous precipitates. Their compositions are intermediate between $\alpha$ $\mathrm{FeOOH}$ (goethite) and $\alpha-\mathrm{Fe}_{2} \mathrm{O}_{3}$ (hematite) ${ }^{34,35}$.

As far as the divalent transition metal ions are concerned, compact tetramers are formed as a result of the condensation ${ }^{28}$. However, $\mathrm{Cu}(\mathrm{II})$ seems to produce $\left[\mathrm{Cu}(\mathrm{OH})_{2}\right]_{\infty}$ edge-sharing chain ${ }^{36}$ due to Jahn-Teller effect typical of $\mathrm{d}^{9}$ ions in octahedral field. At low $\mathrm{pH}$, a cornersharing dimmer $\left[\mathrm{Cu}_{2}(\mathrm{OH})\left(\mathrm{OH}_{2}\right)_{2}\right]^{3+}$ is probably formed ${ }^{37}$ which transforms itself into edge-sharing chain polymers $\left[\mathrm{Cu}_{\mathrm{n}}(\mathrm{OH})_{2 \mathrm{n}-2}\left(\mathrm{OH}_{2}\right)_{2}\right]^{2+}(\mathrm{n}=2,3)$ at higher $\mathrm{pH}^{37,38}$.

In all cases, the kinetics of polymerization in an aqueous medium strongly depend on the charge, size, electronegativity and electronic configuration of the metallic ion ${ }^{39,40}$ : the smaller the charge and the larger the ionic radius the faster will be the process. As a consequence, the dimerization rate constant of the $\mathrm{Fe}(\mathrm{III})$ precursor is rather low $(\mathrm{k}=$ $\left.10^{-1}-10^{-3} \mathrm{M}^{-1} \mathrm{~s}^{-1}\right)$ whereas it is much faster for $\mathrm{Cu}(\mathrm{II}), \mathrm{k}=$ $10^{8} \mathrm{M}^{-1} \mathrm{~s}^{-141,42}$.

By considering these aspects, one can suppose that under the experimental conditions used in this work, Fe(III) undergoes hydrolysis and further polymerization simulta- 


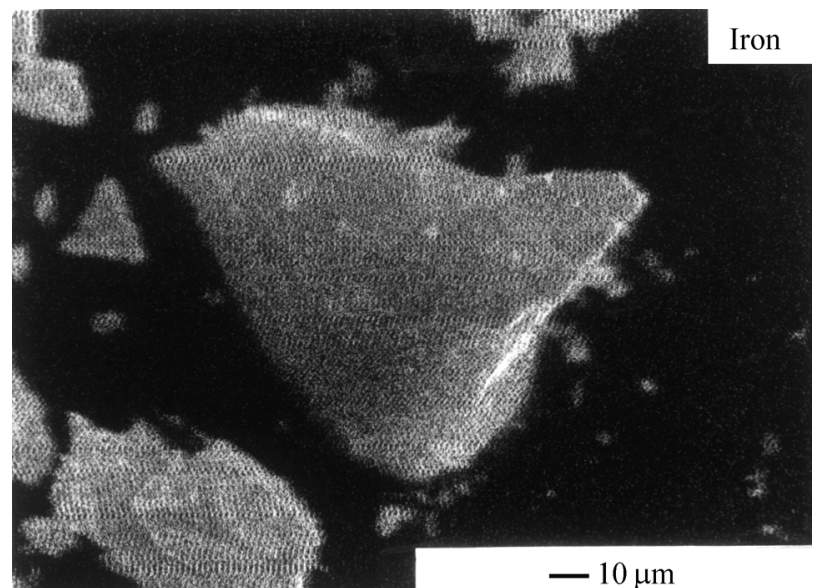

Under heating the plain and doped-IHA produce magnetite. As reported previously ${ }^{9}$, in chromium-doped samples the species are hampered to react, to sinter or to crystallize because their compound are inert. Consequently, these solids are less crystalline and have higher surface areas as compared to the plain materials. On the other hand, in copper-doped samples, the species have higher mobilities and the resulting solids are more crystalline and have lower surface areas than pure magnetite; these effects increase with the amount of copper. However, due to the small amounts of this metal in the sample studied a significant effect was noted only in surface areas.

By comparing the chemical analysis results (Table 2) with our previous work ${ }^{9}$ (in which we typically found values of the $\mathrm{Fe}$ (II) to $\mathrm{Fe}$ (III) molar ratio close to 0.5 , in chromium-doped magnetite) we note that the preparation method as well as the presence of $\mathrm{Na}(\mathrm{I})$ ions slightly delays $\mathrm{Fe}$ (III) reduction probably due to the stronger $\mathrm{Na}-\mathrm{O}$ bonds ${ }^{18}$. In addition, the effect of chromium in the inhibition of the $\mathrm{Fe}$ (III) reduction was not found in the present work; as pointed out earlier ${ }^{9}$, the extent of this process strongly depends on the preparation method of the solids. However, the presence of chromium leads to a decrease in the amount of sodium, suggesting a preference of the spinel structure in accepting $\mathrm{Cr}(\mathrm{III})$ instead of $\mathrm{Na}(\mathrm{I})$ ions. Such behavior can be explained by the Goldschmidt Rules ${ }^{18}$, according to which the ion with the smaller radius or the higher charge will be preferentially incorporated.

In the same way, the surface areas of the plain magnetite are lower than those prepared earlier $\left(33 \mathrm{~m}^{2} / \mathrm{g}\right)^{9}$; again, this fact can be attributed to the differences in the preparation methods which reflect different particles size ${ }^{43}$.

No other phase, besides magnetite, was detected. As wustite is unstable below $575^{\circ} \mathrm{C}^{44}$, it is not probable that this phase could be in the solids produced in the present work. By studying the reduction of iron oxides, it has been noted $^{45}$ that metallic iron is formed directly from magnetite below that temperature, but through the intermediate wustite phase above $575{ }^{\circ} \mathrm{C}$. In addition, according to several authors ${ }^{46,47}$ the lattices of iron catalysts promoted with oxides of trivalent cations of metals are paracrystalline due to endotactic groups $\mathrm{X}_{2} \mathrm{Fe}_{2} \mathrm{O}_{4}(\mathrm{X}=$ trivalent cation) which are statistically distributed in the structure. This can explain the excess of $\mathrm{Fe}(\mathrm{II})$ in doped-solids, as compared to our previous work, and the differences detected in the interplanar spacing values.

Both chromium and copper improve the performance of the catalysts. Chromium acts as a stabilizer but leads to a decrease in the intrinsic activity, in contrast with other works ${ }^{48,49}$ in which the specific activity and activation energy of the iron-based catalysts appear to be about the same with or without $\mathrm{Cr}_{2} \mathrm{O}_{3}$ addition. This can be attributed to the different phases present in each case. As pointed out by Sengupta et $a .^{50}$, the intrinsic activity as well as the 
stability of the catalysts depends on the phases present in the solids. In fact, a $\mathrm{Cr}_{2} \mathrm{O}_{3}$ phase was not detected in this work.

On the other hand, copper improves the intrinsic activity and this effect depends on the amount of this dopant in the solids; the highest value is shown by the sample with $\mathrm{Fe} / \mathrm{Cu}=35$. In the presence of chromium there is a decrease, leading to values near those of the plain magnetite. However, as chromium delays sintering, chromium and copper improve the catalytic performance as a synergetic effect of these dopants.

\section{Conclusions}

Copper improves the performance of the iron and chromium-based catalysts towards the HTS reaction, by increasing the intrinsic activity. This effect increases with the amount of this dopant in solids. It favors sintering leading to solids with low surface areas but in the presence of chromium sintering is delayed and this results in catalysts with higher activity.

\section{Acknowledgement}

The authors are grateful to Professor Fernando Galembeck for his help in characterizing the catalysts. EBQ acknowledges $\mathrm{CNPq}$ for an undergraduate fellowship. The work was performed under the financial support of $\mathrm{CNPq}$ and FINEP.

\section{References}

1. Campbell, J.S.; Young, P.W. In Catalysis Handbook; Wolfe Scientific Books; London, 1970.

2. Newsome, D.S. Catal. Rev.-Sci. Eng. 1980, 21, 275.

3. Bohlbro, H. In An Investigation on the Kinetics of the Conversions of Carbon Monoxide with Water Vapor over Iron Oxide based Catalysts; The Haldor Topsoe Laboratory, Vedback, 1960.

4. Andreev, A.; Idakiev, V.; Kostov, K.; Gabrovska, M. Catal. Lett. 1995, 31, 245.

5. Li, Y.; Wang, R.; Zhang, J.; Cahng, L. Catalysis Today 1996, 30, 49.

6. Xue, E.; O’Keefe, M.; Ross, J.R.H. Catalysis Today 1996, 30, 107.

7. Souza, M.O.G.; Quadro, E.B.; Rangel, M.C. Química Nova 1998, 21, 428.

8. Idakiév, D. React. Kinet. Catal. Let. 1988, 33, 119.

9. Rangel, M.C.; Sassaki, R.M.; Galembeck, F. Catal. Lett. 1995, 33, 237.

10. Abreu Filho, P.P.; Pinheiro, E.A.; Galembeck, F. Reactivity. of Solids. 1987, 3, 241.
11. Fergl; F.; Anger, V.; Oesper, R.E. Inorganic Analysis; Elsevier, Amsterdam, 1972.

12. Vogel, A.I. Quantitative Inorganic Analysis, Longman, London, 1961.

13. Bennet, H.; Reed, R.A. Chemical Methods of Silicate Analysis. A Handbook. Academic Press, London, 1971.

14. Basolo, F.; Johnson, R. Química de los Compuestos de la Coordinación; Editorial Reverté, S.A., Barcelona, 1980.

15. Styles, A. Catalyst Manufacture. Laboratory and Commercial Preparations; Marcel Dekker, Inc . New York, 1983.

16. ASTM card no. 19269.

17. Dry, M.E.; Ferreira, L.C. J. Catal. 1967, 7, 352.

18. Ringwood, A.E. Geochimica et Cosmochimica Acta 1955, 7, 189.

19. McClure, D.S. J. Phys. Chem. Solids 1957, 3, 311.

20. Silverstein, R.; Basslerand, G.C.; Morrill, T.C. Spectrometry Identification of Organic Compounds; John Willey and Sons, New York.

21. Niquist, R.A.; Kagel, R.O. Infrared Spectra of Inorganic Compounds, Academic Press Inc.; Orland, 1971.

22. Rangel, M.C.; Galembeck, F. J. Catal. 1994, 145, 364.

23. Pascal, P. Nouveau Traité de Chimie Minérale. Tome XVII.; Masson et Cie, Paris, 1967.

24. Bhattacharga, S.K.; Ramachandram, V.S.; Ghosh, J.C. Advances in Catalysis 1957, 9, 114.

25. Matijevic, E.; Scheiner, P. J. Colloid Interf. Sci. 1978, 63, 509.

26. Sidhu, P.S. ; Gilkes, R.J.; Posner, A.M. J. Inorg.Nucl. Chem. 1978, 40, 429.

27. Baes Jr., C.F.; Mesmer, R.E. The Hydrolysis of Cations. John Willey and Sons, New York, 1976.

28. Livage, J.; Henry, M.; Sanchez, C. Progr. Sol. State Chem. 1988, 8, 259.

29. Burguess, J. Metal Ions in Solution; John Willey and Sons, New York, 1978.

30. Blesa, M.A.; Matijetic, E. Adv. Colloid Interf. Sci. 1989, 29, 173.

31. Segal, D.L. J. Chem.Tech. Biotechnol. 1984, 24, 355.

32. Khoe, G.H.; Brown, P.L.; Sylva, R.N.; Robins, R.G. J. Chem. Soc. Dalton Trans. 1986, 1901.

33. Stunzi, H.; Spiccia, L.; Rotzinger, F.P.; Marty., W. Inorg.Chem. 1988, 28, 66.

34. Rajendram, S.; Rao, Y.S.; Maiti, H.S. J.Mater. Sci. 1982, 19, 2709.

35. Prasad, S.V.S.; Rao, V.S. J. Mater. Sci. 1984, 19, 3266.

36. Perrin, D.D. J. Chem. Soc. 1960, 3189.

37. Sylva; R.N.; Davidson, M.R. J. Chem. Soc. Dalton Trans. 1979, 232.

38. Eigen, M. Pure Appl. Chem. 1963, 69, 97. 
39. Kruger, H. Chem. Soc. Rev. 1982, 11, 227.

40. Lutz, B.; Wendt, H. Chimia, 1973, 27, 575.

41. Wendt, H. Chimia 1973, 27, 575.

42. Viswanath, R.P.; Viswanath, B.; Sastri, M.V.C. Thermochim. Acta 1976, 16, 240.

43. Matijevic, E.; Sapieszco, R.S.; Melville, J.B. J. Colloid Interf. Sci. 1975, 50, 567.

44. Graham, M.J.; Channing, D.A.; Swallow, G.A.; Jones, R.D. J. Mat. Sci. 1975, 10, 1175.

45. Ray, H.S.; Kundu, N. Thermochim. Acta 1986, 101, 107.
46. Hosemann, R; Preisinger, A.; Vogel, W. Ber. Bunsengs. Phys. Chem. 1966, 70, 796.

47.Ludwiczek, H.; Preisinger, A.; Fischer, A.; Hosemann, R.; Schonfeld, A.; Vogel, W. J. Catal. 1978, 51, 326.

48. Markina, M.I.; Bareskov, G.K; Ivanovskii, F.P.; Lyndkovskaya, B.J. Kinet. Katal. 1961, 2, 867.

49. Danielczyk, N.; Haber, J. Rocz. Chem. 1977, 51, 507.

50. Sengupta, G.; Prasad, K.; Sinha, S.C.; Sem, S.P. Indian J. Chem. 1979, 18, 392. 